\title{
USING SPACE SURVEY MATERIALS FOR MODELING HYDRODYNAMIC ACCIDENTS AT MINING ENTERPRISES IN KAZAKHSTAN
}

\author{
M.Ye. Rakhymberdina ${ }^{1}$, E.V. Grokhotov ${ }^{2}$, Zh.A. Assylkhanova ${ }^{1}$, M.M. Toguzova ${ }^{1}$ \\ ${ }^{1}$ D. Serikbayev East Kazakhstan Technical University, Ust-Kamenogorsk, Kazakhstan - (MRahymberdina, \\ ZhAssylkhanova)@ektu.kz; Marzhan123@mail.ru \\ ${ }^{2}$ Geosat LLP, Ust-Kamenogorsk, Kazakhstan - info@geosat.biz
}

Commission V, WG V/7

KEY WORDS: Hydraulic Structures, Hydrodynamic Accidents, Satellite Images, Digital Elevation Model, 3d Modelling

\begin{abstract}
:
The timeliness of using modern computer programs for modelling flood zones, the consequences of hydraulic accidents, dam breakthroughs, flood and flood forecasting in a complex system of rivers and channels for the prevention of hydro meteorological emergencies is beyond doubt. The use of BIM technologies will make it possible to move from point-based flood risk assessments to areal ones, which will significantly improve the reliability of planned measures to prevent natural and anthropogenic emergencies. The purpose - to perform works on modelling of hydrodynamic accident and forecast of its development by the example of tailings dumps in concentration plant in East Kazakhstan. As the initial data - digital model for the area of work, technical reports on engineering-hydrographical survey, topographic-geodetic works, engineering-geological survey, high-resolution satellite images in a panchromatic survey mode. On the basis of geoinformation modelling methods with use of initial and remote sensing data, final digital terrain model was built in Digital software. The method based on direct hydrodynamic modelling of area flooding was used to calculate hydrodynamic accidents, to model the dynamics of area flooding because of tailings dam break in several levels. The practical result is numerical hydrodynamic modelling of dynamics flooding area because of partial destruction, erosion of embankment dam of tailings concentrator, total area and extent of flooding, as well as the area and depth of partially flooded buildings of residential development was estimated, thematic maps of flooded area were created, as well as maps of water passage with flow velocities during the hydrodynamic accident.

Thus, the application of advanced space imagery, GIS technologies in full measure allow for simulating the occurrence, development of hydrodynamic accidents in structures, to determine area, time of flooding.
\end{abstract}

\section{HYDRAULIC STRUCTURES AND DETERMINATION OF THE DEVELOPMENT OF PROCESSES ON THEM}

\section{INTRODUCTION}

As the world experience shows, the probability of accidents at hydraulic structures has increased over the last 15 years, which is primarily associated with the passage of floods exceeding the design water levels. Among technogenic disasters, hydrodynamic accidents take one of the first places according to the value of consequences and economic damage; therefore, using modern computer programs for modeling flood zones, consequences of hydro technical accidents, dam breaks, floods and forecasts for the purposes of emergency prevention is of topical importance. Only complex use of modern computer systems, remote sensing materials and modeling methods allows approaching the predicted model to the real one, taking into account all factors affecting the development process, assessing the scale of consequences and taking preventive measures to prevent accidents in advance.

In addition to solving environmental problems, modern remote sensing methods are able to solve a whole range of tasks for mining enterprises, such as the creation and maintenance of databases of cartographic, analytical, situational and managerial information.

\subsection{The current state of the HS on the territory of the Republic of Kazakhstan}

Nowadays there are 643 HS located on the territory of the Republic of Kazakhstan among which 340 structures are used directly for industrial and economic purposes (for the needs of energy, agriculture, etc.) including 270 large and small reservoirs with complexes of hydraulic structures where 62 and 208 reservoirs are of republican and local significance correspondingly. In accordance with the Water Code of the Republic of Kazakhstan 57 reservoirs and 29 water retaining structures are included in the list of special objects of strategic importance of the country. There are also about 820 rivers with a length of 40 kilometers or more, on which floods occur under the influence of anthropogenic and natural conditions (Legalacts, 2017).

Given the natural and climatic conditions, floods are an annual phenomenon on the territory of the country, but their development and scale vary greatly in different years significantly. Over the past 15 years more than 320 floods have been recorded in Kazakhstan as a result of both natural and "human" factors, of which $70 \%$ are "spring floods" (which as a rule can be predicted), $30 \%$ were caused by rains and $10 \%$ had other reasons.

The existence of a large number of pressurized ground HS (70\%) accumulating significant reserves of water energy creates a potential threat to the safety of industrial and economic infrastructure and the biosphere. Considering that the average "age" of the HS is more than 50 years, as well as a large number of very old, built and put into operation for more than 
70-80 years, often without an "owner", the probability of accidents at the HS begins to rise sharply over time, so the danger of their destruction increases and many require immediate reconstruction and repair. The actual wear of most hydraulic engineering facilities today is $55-75 \%$ or more.

Most of the reservoirs are designed for the so-called seasonal water flow regulation. A considerable part of HS belong to the $5^{\text {th }}$ category of importance (over $85 \%$ of the total number of structures), as a rule erected by economic method (i.e. without development of specialized design documentation and without involvement of specialized specialists) (Legalacts, 2017). Most of these structures have been in operation without repair or reconstruction for 40-60 years or more and are objects of high risk.

According to the research conducted by the specialists of the Ministry of Emergency Situations of the Republic of Kazakhstan, most of the hydraulic structures namely for 28 large objects restoration is needed. A quarter of all the largest HS (61 reservoirs, 91 hydro system and main canals) are in state ownership. Other hydraulic structures are managed by municipal, large industrial and agricultural enterprises.

To ensure safe operation of hydraulic structures, it is necessary to use information modeling as a tool for predicting various situations at a facility and optimizing costs not only for construction, but also for operation throughout the life cycle of the facilityю Such advanced technologies are BIMtechnologies.

Building Information Modeling (BIM) is the newest stage of development of the construction industry, which refers to the process of designing, constructing and operating of buildings and structures, using a single system of creating 3D-models (Nur et al., 2017). Application of BIM-technology in Kazakhstan is called TIMCO - technology of information modeling of construction objects (1-p.kz, 2017).

The features of modeling primarily depend on the specifics of the tasks to be solved and actually determine what information is necessary to have "at the input" and what information is necessary "at the output" for each stage of the production of works (Bryde et al., 2013).

\subsection{Selection of Space Survey Materials for Modeling a Hydrodynamic Accident}

Operational or archived space imagery data are increasingly used to organize environmental monitoring and modeling of natural and anthropogenic environmental impacts, as well as to provide rescue and recovery operations.

The application of remote sensing data increases the efficiency of special operations in the areas of possible or existing emergencies (emergencies):

- obtaining an up-to-date, highly accurate, and illustrative electronic geospatial database for the operational area and location of an emergency;

- obtaining emergency forecasts;

- efficient detection of emergency localization zones and on-line monitoring of emergency development at all stages;

- recognition in the optical range and radar interferometry of local emergencies: faults, taluses, landslides, mudslides, subsidence, heaving, erosion, as well as related destruction of dams, embankments, destruction of hydraulic structures, etc;

- multi-temporal forecasts, as well as modeling of the development and spread of emergencies (modeling of flooding, spreading of toxic substances, in environments, on the Earth's surface, etc.)

- generation of different scale situation plans of the region as a whole (settlements, highways, orography, hydrography) to a specific settlement (streets, buildings, rivers, relief) in the form of vector digital maps to overlay space images to support operations and situation analysis;

- high-precision mapping of consequences of emergencies with reception of vector digital layers of destroyed production and other buildings, communications;

- damage assessment;

- construction of 3D models of potentially hazardous facilities, life support facilities of population using space stereo survey.

Based on world practice (Piloyan et al., 2017), the following technology of providing the crisis management system with the remote sensing data is used:

- archival satellite imagery to obtain the basic spatial basis of the territory;

- high-resolution operational shooting;

- operational ultra-high resolution shooting;

- operational radar survey on request.

\subsection{Object of Research and Basic Data}

The object of the research is a tailings dump of the concentration plant located in Shemonaikha district of East Kazakhstan region, Republic of Kazakhstan (Fig. 1).

The following elevations are characteristic of the object under consideration:

1) For the south-western tailings dump of the concentrating plant at the level of the upper tier of the bund wall - 366.5 $368.0 \mathrm{~m}$; at the bottom of the pond $-362 \mathrm{~m}$; at the foot of the tailings dump - $325 \mathrm{~m}$. The height of bund wall of the tailings dump of the concentration plant is relative to the bottom of the pond $4.5-6 \mathrm{~m}$.

2) For the north-eastern tailings dump of the concentrating plant at the level of the upper tier of the bund wall - $380-383 \mathrm{~m}$; at the bottom of the pond $-376 \mathrm{~m}$; at the foot of the tailings dump - $360 \mathrm{~m}$. The height bund wall of the tailings dump of the concentration plant is relative to the bottom of the pond $4-7 \mathrm{~m}$.

The dam is made of bulk loam. The area of the tailings dump is as follows:

1) For the south-west tailings dump at $366 \mathrm{~m}$ level 758 thousand $\mathrm{m}^{2}$;

2) For the north-east tailings dump at the level of $379.5 \mathrm{~m}$ 805 thousand $\mathrm{m}^{2}$;

The volume of water in the tailings pond is:

1) For the southwest tailings pond from the $362 \mathrm{~m}$ mark to the $366 \mathrm{~m}$ mark is 1555 thousand $\mathrm{m}^{3}$;

2) For the north-east tailing dump from the mark of $376 \mathrm{~m}$ to the mark of $379.5 \mathrm{~m}$ it is 1967 thousand $\mathrm{m}^{3}$;

Space images of the area were used to present the results of modeling.

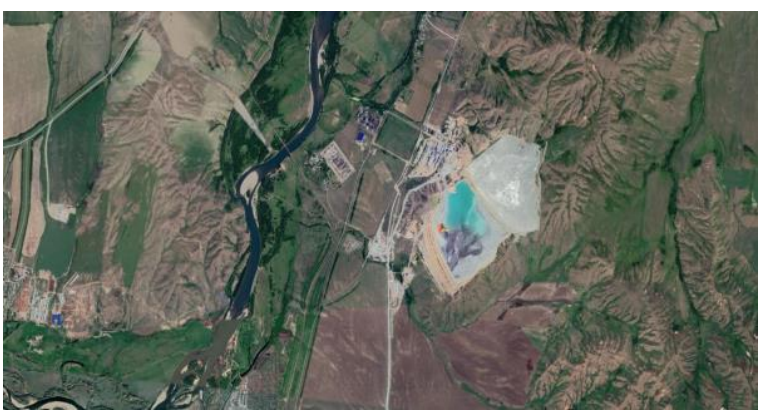

Figure 1. Position of the tailings dump concentration plant on the map (view from space). 


\subsection{Methods, Approaches and Tools for Modeling and} Calculating Hydrodynamic Accidents

The method based on direct hydrodynamic modeling of area flooding was used to calculate hydrodynamic accidents and model the dynamics of area flooding as a result of a break of the tailings dam (Eremin et al., 2006).

The main tasks to be solved in the above approach are:

- calculation and refinement of the catchment area;

- calculation of characteristic drainage features;

- modeling the dynamics of flooding territories, taking into account the influence of physical factors, features of the relief and terrain;

- modeling catastrophic floods and emergencies at hydraulic structures (dam breaks)

- forecasting the consequences in flooded areas.

The primary factors influencing the dynamics of flooding are surface as well as underground water sources, terrain features, characteristics of the underlying surface, internal viscous friction, wind impact, Earth rotation, evaporation (Dyakonova et al., 2014).

These factors can be effectively taken into account in shallow water model created on the basis of hydrodynamic equations by vertical coordinate averaging method (Saint-Venant equations) (Berdyshev et al., 2021, Khrapov et al., 2020). To perform modeling and calculations, the hardware-software complex "EMGIS" was used, which includes modern supercomputer systems, parallel computing technologies, as well as effective calculation algorithms. The computer model is based on the latest high-efficiency mathematical calculation algorithm (CSPH-TVD method) capable of simulating surface water dynamics on an arbitrary terrain, taking into account various physical factors (Evstigneev et al., 2006).

Modeling of the hydrodynamic accident was carried out on the basis of the digital relief model, which construction was carried out with the use of Digitals program. On the basis of geoinformation modeling methods with the use of input data in formats (.dwg, .dxf) and remote sensing data (SRTM-1), the final digital terrain model was develop. At the same time, the design solutions for reconstruction of the tailings storage facility of the concentration plant were taken into account (Fig. $2,3)$.

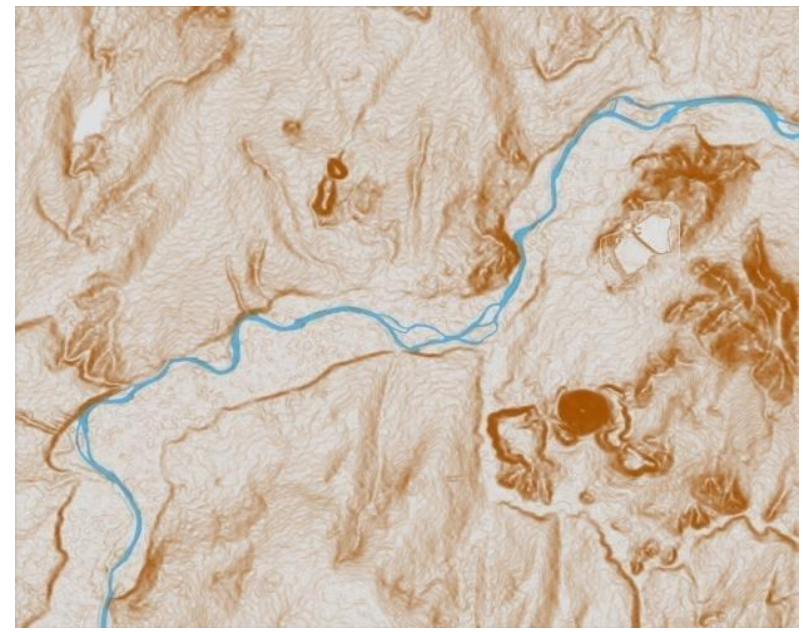

Figure 2. The topography of the simulated area. The size of the simulated area $21 \times 19 \mathrm{~km}$. The contour interval is $0.5 \mathrm{~m}$.

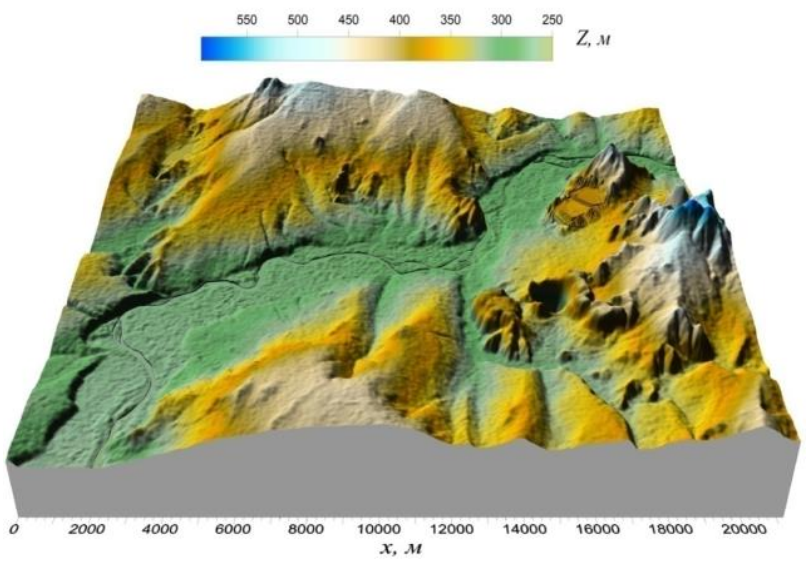

Figure 3. DEM of the simulated area (3D representation).

\section{MODELING OF HYDRODYNAMIC ACCIDENTS AND FORECAST OF ITS DEVELOPMENT AT THE TAILINGS STORAGE FACILITY}

\subsection{Modeling of a Hydrodynamic Accident and Forecast of its Development at a Tailings Dump}

When modeling hydrodynamic accidents at the site, the following levels or stages are projected, which are considered as the main ones:

The initial water level in the tailings pond of the concentration plant before modeling is:

- for the south-western part - $366.0 \mathrm{~m}$ (the maximum depth of the pond is $4 \mathrm{~m}$ );

- for the north-eastern part - $379.5 \mathrm{~m}$ (the maximum depth of the pond is $3.5 \mathrm{~m}$ ).

At the initial moment of time, as a result of mechanical local damage (damage by an excavator during excavation), a channel (trench) is formed 1-2 m wide (across the dam), several tens of meters long (from the bottom of the pond to the outer edge of the dam) and several meters deep from the top of the dam, thus forming a channel with a water flow of a breakthrough 1-2 m deep.

Further, as a result of the impact of the water flow, the bottom of the channel is washed away and the side walls of the channel collapse with the formation of a natural slope. After the formation of the hole, the mudflow (a mixture of water and soil) rushes to the foot of the dam and subsequently forms a flooding zone in the vicinity of the tailings dump (Khrapov et al., 2010). When modeling the dynamics of flooding, several variants (models) of the formation of a breach in various sections of dams in the southwestern and northeastern parts of the tailing dump were considered (Fig. 4, a):

Model 1. The passage is formed on the outer dam of the southwestern tailing dump of the concentrator plant:

a) the central part of the dam, (Model 1a), westerly direction of the flow (Fig. 4, b);

b) southern part of the dam (Model 1b), southward flow direction (Fig. 4, c);

c) northwest part of the dam (Model 1c), westerly flow (Fig. 4, d). Model 2. The passage is formed on the outer dam of the northeastern tailings dam (Model 2), the southern direction of the flow (Fig. 4, e).

Model 3. The passage is formed on the inner dam between the southwestern and northeastern parts of the tailing dump (Model 3) (Fig. 4, f). After the formation of this passage, water begins to flow from the upper pond to the lower one, which overflows and begins to overflow over the outer dam in a westerly 
direction. As a result of this process, the washaway of the dam occurs and a hole is formed in the vicinity of the northwestern part of the dam, as in model 1c.

For modeling of washaway and flooding of areas, the parameters of the dam are taken, in which the upper tiers of dams, which will be eroded, consist of of fill soils (tailings). Tail parameters are shown in the Tab. 1.

\begin{tabular}{|c|c|c|}
\hline Characteristics & $\begin{array}{c}\text { Unit of } \\
\text { measurement }\end{array}$ & Magnitude \\
\hline Tailings particle density & $\mathrm{t} / \mathrm{m}^{3}$ & 3.59 \\
\hline Bulk weight of tailings & $\mathrm{t} / \mathrm{m}^{3}$ & 1.30 \\
\hline $\begin{array}{l}\text { Weighted average } \\
\text { geometric coarseness }\end{array}$ & $\mathrm{mm}$ & 0.028 \\
\hline $\begin{array}{l}\text { Solid phase/Liquid phase } \\
\text { tailings pulp }\end{array}$ & $\%$ solid & $1: 6$, or 14.3 \\
\hline $\begin{array}{l}\text { Granulometric composition } \\
\text { of tailings: } \\
-0.14+0.1 \mathrm{~mm} \\
-0.1+0.071 \mathrm{~mm} \\
-0.071+0.045 \mathrm{~mm} \\
-0.045+0.030 \mathrm{~mm} \\
-0.030+0.020 \mathrm{~mm} \\
-0.020+0.001 \mathrm{~mm} \\
-0.010+0.0 \mathrm{~mm} \\
\end{array}$ & $\begin{array}{l}\% \\
\% \\
\% \\
\% \\
\% \\
\% \\
\%\end{array}$ & $\begin{array}{c}2.95 \\
5.80 \\
11.80 \\
13.55 \\
16.90 \\
6.85 \\
41.65 \\
\end{array}$ \\
\hline $\begin{array}{l}\text { Mineral composition of } \\
\text { tailings: } \\
\text { Chalcopyrite } \\
\text { Sphalerite } \\
\text { Galenite } \\
\text { Pyrite } \\
\text { Waste rock }\end{array}$ & $\begin{array}{l}\% \\
\% \\
\% \\
\% \\
\%\end{array}$ & $\begin{array}{c}0.8-1.5 \\
0.8-2.0 \\
0.3-0.5 \\
20-45 \\
50-77\end{array}$ \\
\hline
\end{tabular}

Table 1. Characteristics of the tailings forming the dam.

The following soil parameters are used for modeling of the dam scour and flooding: median coarseness, porosity, and density of soil particles.

\subsection{Calculation of Flooding Zones as a Result of Hydrodynamic Accident Development at the Tailings Concentrating}

The distribution of depths and velocities in the flood zones is displayed in a different translucent color. The minimum value by which the flooding boundary is constructed is $0.05 \mathrm{~m}$ for depths and $0.05 \mathrm{~m} / \mathrm{s}$ for velocities (the border color is red).

The simulation time was 10 hours from the moment of the accident. During this time, the flow of water from the tailings dump reaches the vicinity of the settlement of Krasny Yar along the riverbed of the Uba river. After the dam is breached, the main flow of water moves westward to the Uba River, flooding only roads and industrial development areas on its way. The time of arrival of the breakthrough wave to the Uba riverbed is 1-3 hours, depending on the proran models. Further, the stream moves along the riverbed in the direction of the settlement of Krasny Yar, flooding the islands and floodplain of the river on its way.

Model 3 is the strongest version of the breakthrough and flooding of the environs of the tailings concentrator, because in this case the water of the upper and lower ponds participates in the flooding. The maximum flooding depth and flow velocity in this case reach $5 \mathrm{~m}$ and $5 \mathrm{~m} / \mathrm{s}$, respectively.

The maximum area of flooding of the land territories adjacent to the tailings storage of the processing plant (excluding the Uba riverbed) is $5.58 \mathrm{~km}^{2}$. The length of the flooding zone, excluding the riverbed and floodplain of the Uba River, is 2.5 $5 \mathrm{~km}$, depending on the models of the breakthrough and about $25 \mathrm{~km}$, taking them into account.
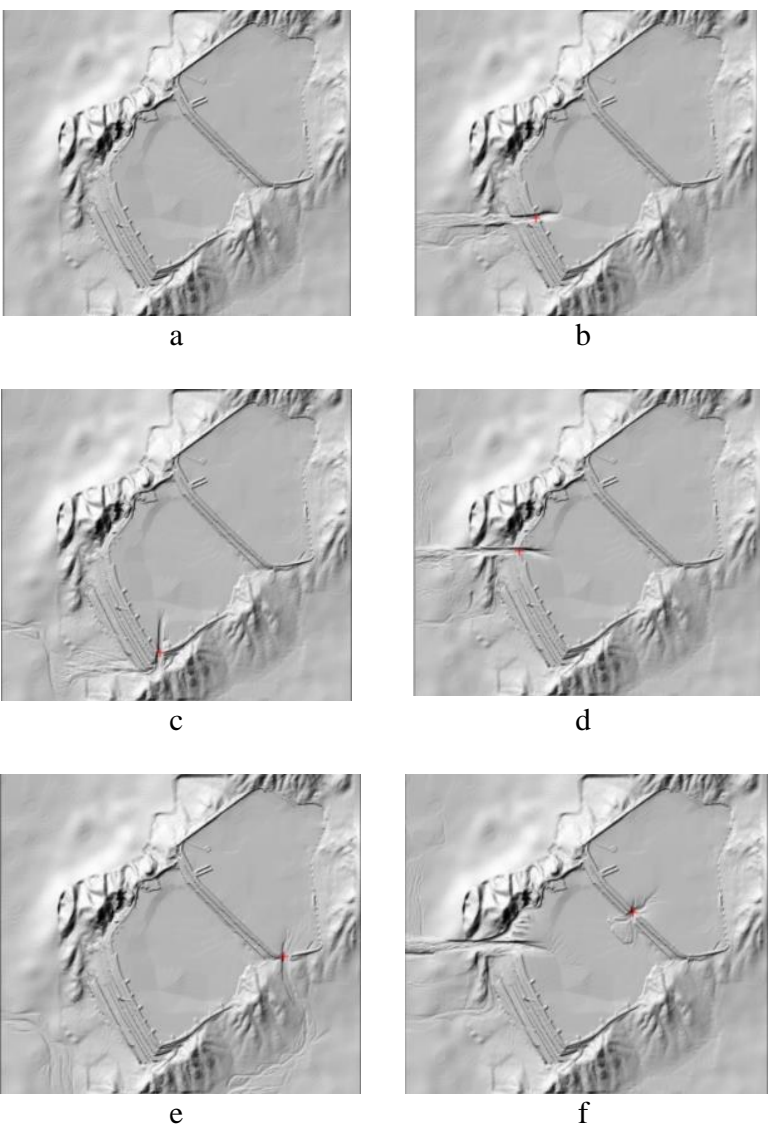

Figure 4. Structure of the passage in the tailings dump of the concentrating plant at the final stage of the hydrodynamic accident in various models. The position of the control points is shown by the red symbol: a) initial state, b) model 1a, c) model $1 \mathrm{~b}, \mathrm{~d})$ model 1c, e) model 2, f) model 3.

\subsection{Calculation of Passage Formation (Dam Failure Process)}

Numerical modeling of the process of dam failure as a result of a hydrodynamic accident at a tailings storage facility was based on the algorithm of self-consistent calculation of the dynamics of flooding and soil erosion, including models and a calculation method for the formation of a passage (Khrapov et al., 2010). The results of calculations for Model 3, as well as the structure of the passage formed during the development of the hydrodynamic accident in the tailings pond are shown in Figures 5-8, where the flood boundary is highlighted in red. 


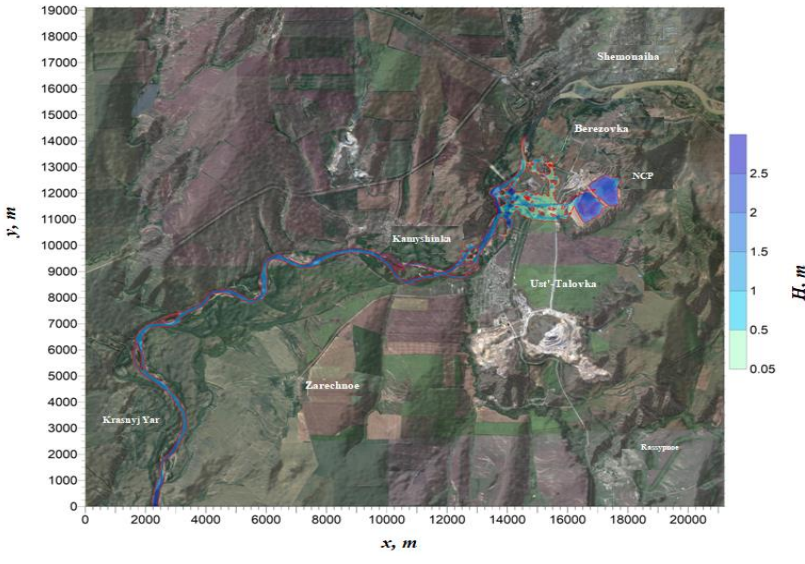

Figure 5. Depth distribution in the flood zone during the development of a hydrodynamic accident (Model 3) at the tailing dump of the processing plant.

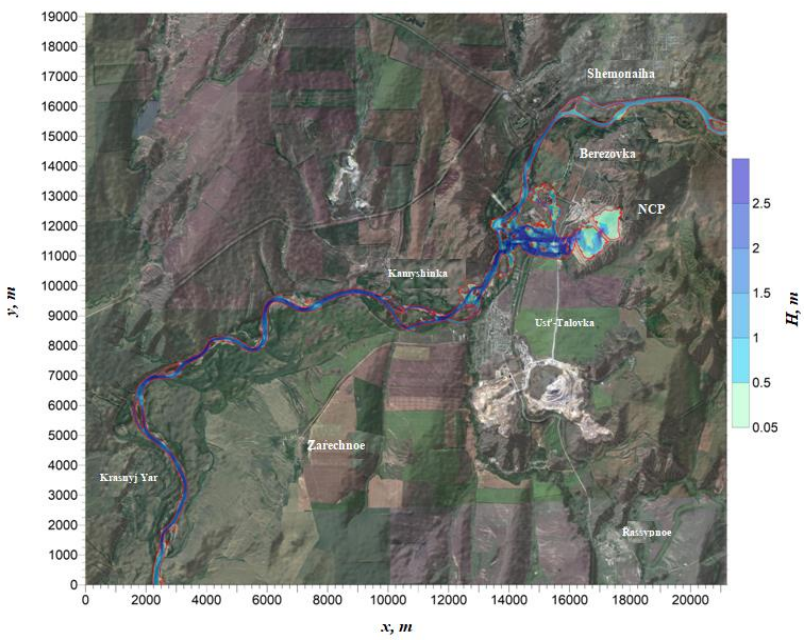

Figure 6. Depth distribution in the flood zone during the development of a hydrodynamic accident (Model 3 including the river) at the tailings storage facility of the concentrator.

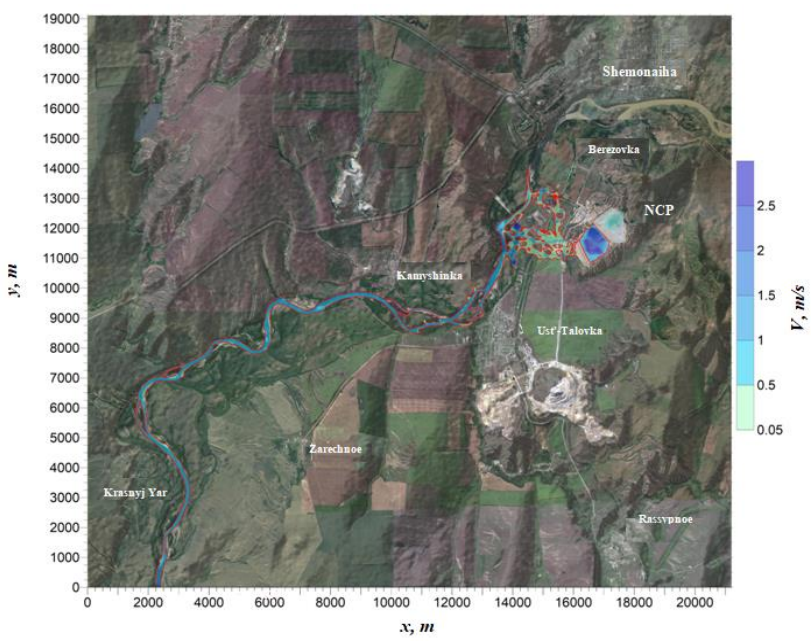

Figure 7. Distribution of the current velocity in the flooding zone during the development of a hydrodynamic accident (Model 3) at the tailing dump of the processing plant.

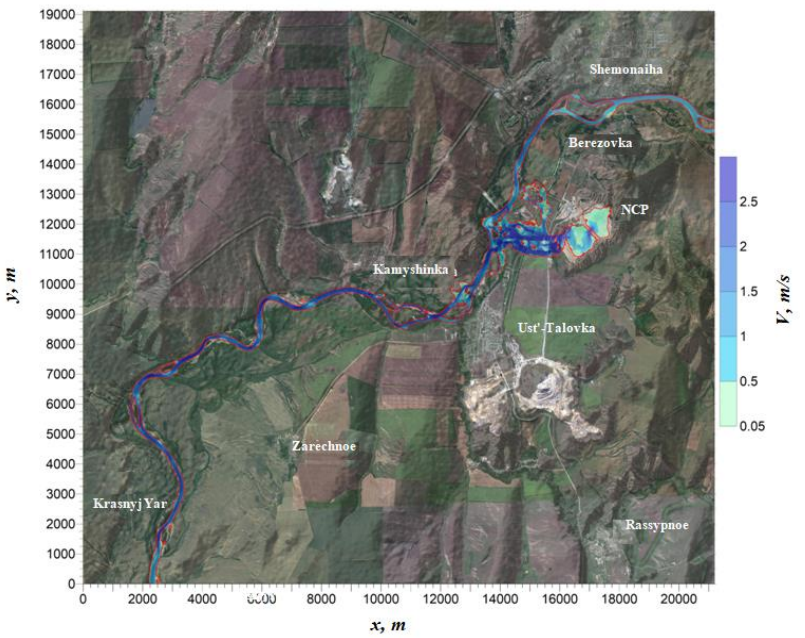

Figure 8. Distribution of the current velocity in the flooding zone during the development of a hydrodynamic accident

(Model 3 taking into account the river) at the tailing dump of the processing plant.

As can be seen in the figures 5-8, the time dependence of water volume in the tailings $V_{\text {damb }}(t)$ and in the flooding area $V_{\text {flood }}(t)$ is clearly traced. So 4 hours after the beginning of the breakthrough the volume of water in the tailing dump diminishes twice, and after 16 hours less than 5 thousand $\mathrm{m}^{3}$ remain in the tailing dump, while the water depth in the tailing dump is less than $5 \mathrm{~cm}$.

Similarly, the volumetric flow rate of water $Q(t)$, flowing out through the passage of the tailings dam, depends on time. The maximum level of water discharge (flow rate) reaches values of $13.6 \mathrm{~m}^{3} / \mathrm{s}$ by the time $\mathrm{t}=100 \mathrm{~min}$. The maximum area of flooding is $5.58 \mathrm{~km}^{2}$. The flood zone shows on Fig. 9.

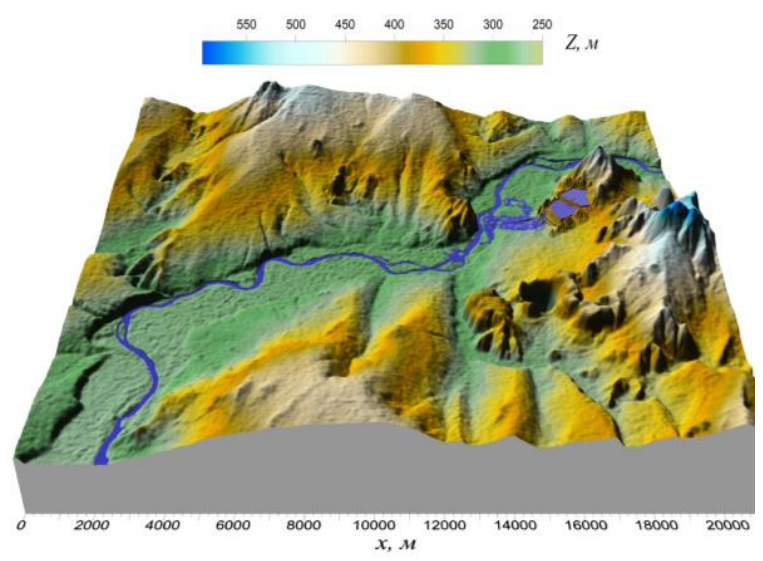

Figure 9. Flooded area during the development of a hydrodynamic accident at the tailings dump of the concentrator on the three-dimensional map, scale 1: 25000

From the calculations carried out, it can be seen that the maximum values of the velocity and depth of the flow in the channel of the passage in the vicinity of the control point are $3.2 \mathrm{~m} / \mathrm{s}$ and $8.1 \mathrm{~m}$, respectively. The level of the channel passage is broken in the vicinity of the control point decreases by $7 \mathrm{~m}$ to its minimum value of $369 \mathrm{~m}$ in $300 \mathrm{~min}$. The width of the hole in the vicinity of the control point increases to its maximum value of $15.7 \mathrm{~m}$ in $300 \mathrm{~min}$. 


\section{RESULTS AND DISCUSSION}

As a result of the executed research on modeling of the hydrodynamic accident and the forecast of its development on a tailings dump of concentrator have been made:

- a digital relief model was created for the purposes of hydrodynamic modeling, elevation matrices of the simulated area were built based on remote sensing data, topographic maps and the provided 2D drawings of the tailings dump territory, engineering and geological survey materials were collected and analyzed, KOMPSAT-3 optical space survey data were received and processed;

- numerical hydrodynamic modeling of the flooded areas dynamics as a result of partial destruction and erosion of the enclosing dam of the tailings dump was carried out;

- maps of water depth and flow velocity distribution in the flooded areas were created;

- thematic maps of under flooding zones were created as well as maps of water passage in case of hydrodynamic accident with indication of flow velocities.

- dimensions of the passage and the flow velocity in the passage channel were determined. The total area and extent of flooding, as well as the area and depth of partially flooded residential buildings were assessed. The following characteristics of the hydrodynamic accident are obtained:

1 The size of the passage - width $15.7 \mathrm{~m}$, length $250 \mathrm{~m}$, maximum depth $3.2 \mathrm{~m}$.

2 The high speed of water flow in the channel of the passage is $8.1 \mathrm{~m} / \mathrm{s}$.

3 The maximum flooded area adjacent to the tailing dump of the concentrator is $5.58 \mathrm{~km}^{2}$ (excluding the Uba river bed). The length of the flooded area excluding the Uba river bed and floodplain is $2.5-5.0 \mathrm{~km}$ depending on the failure models, and about $25 \mathrm{~km} \sigma$ taking them into account. The flooding time is 1-3 hours. Maximum water depth in the flooded area $4.8 \mathrm{~m}$. Maximum flow velocity in the flooded area $6.3 \mathrm{~m} / \mathrm{s}$.

4 Area of partially flooded territories of industrial and residential buildings: 94 thousand $\mathrm{m}^{2}$ with a depth of $0.05-0.5 \mathrm{~m}$ and a flow rate of $0.5-2.0 \mathrm{~m} / \mathrm{s} ; 63$ thousand $\mathrm{m}^{2}$ with a depth of $0.5-1.5 \mathrm{~m}$ and a flow rate of 2.5-3.5 m/s.

\section{CONCLUSIONS}

The application of modern technologies of space footage as well as technologies from related branches of modern science allows solving numerous problems in the field of modeling, forecasting and analysis of possible emergency situations, which allows enterprises of mining industry to minimize the material and environmental damages. What is more, the application of modern technologies allows to model the occurrence and development of hydrodynamic accidents on hydraulic structures, to define the area and time of flooding, which leads to the safe exploitation of a hydraulic structure.

BIM-technologies play an enormous importance in the modern information world throughout the life cycle of the object, the transition to these technologies in Kazakhstan is planned to be completed by 2023 , which will allow high-quality simulation of objects, taking into account all components affecting the durability of the object. Thus, based on the work performed, it should be noted that for the successful operation of hydraulic structures and the prevention of emergencies, it is necessary to keep current accounting and continuous space monitoring of facilities using GIS, BIM-technology, models of which over time and conditions have been adjusted and used throughout their operation.

\section{REFERENCES}

Berdyshev, A.S., Abduramanov Z.A., Bliyeva D.N., Akhtayeva N.S., 2021: A brief overview of modern research of the processes dynamics in unsteady water ows using the shallow water equation. Journal of Mathematics, Mechanics and $\begin{array}{llll}\text { Computer Science, } & \text { (S.l.), } & 112 & \text { (4), }\end{array}$ doi.org/10.26577/JMMCS.2021.v112.i4.15

Bryde, D., Broquetas, M., Volm, J.M., 2013: The project benefits of Building Information Modeling (BIM). International Journal of Project Management. 2013. Vol. 31. p. 971-980. doi.org:10.1016/j.ijproman.2012.12.001

Dyakonova, T.A., Pisarev, A.V., Khoperskov, A.V., Khrapov S.S., 2014: Mathematical model of surface water dynamics. The Science Journal of Volgograd State University. Series 1: $\begin{array}{lllll}\text { Mathematics. } & \text { Physics, } & 1 & \text { (20), } & \text { 35-44. }\end{array}$ doi.org/10.15688/jvolsu1.2014.1.4

Eremin, M.A., Khoperskov, A.V. 2006: Computer model of Volzjskay dam-break. The Science Journal of Volgograd State University. Series 1: Mathematics. Physics. 2006.10. 139-142, DOI: $10.0000 /$ cyberleninka.ru/article/n/kompyuternaya-modelproryva-volzhskoy-plotiny

Evstigneev, N.M., 2006: A finite-volume TVD Riemann solver for the 2D shallow water equations, Numerical Methods and Programming, 2006, 7 (1), 108-112. DOI: 10.26089/NumMet.Journal or

https://www.elibrary.ru/item.asp?id=9273218

Khrapov, S.S., Khoperskov, A.V., 2020: Application of Graphics Processing Units for self-consistent modelling of shallow water dynamics and sediment transport. Lobachevskii Journal of Mathematics, 41 (8), 1475-1484 DOI:10.1134/S1995080220080089

Khrapov, S.S., Khoperskov, A.V., Eremin, M.A., 2010: Modeling of surface water dynamics: monograph. Volgograd: Volgograd State University Press. - 131 pp. ISBN 978-5-96690800-3.

Legalacts, 2017: Law Concept of the Republic of Kazakhstan "On the Safety of Hydraulic Structures", URL: https://legalacts.egov.kz/npa/view?id=1787687 (Accessed 26 September, 2017)

1-p.kz, 2017: The concept of implementation of information modeling (BIM) in the construction industry of the Republic of Kazakhstan. URL: http://l-p.kz. (Accessed 3 March, 2017)

Nur, E.M., Rozana, M.S., Hamizah, L.B., Tajul, A., 2017: International Conference on Research and Innovation in Information Systems (ICRIIS), 1-7 (2017)

Piloyan A., Konečný M., 2017: Semi-Automated Classification of Landform Elements in Armenia Based on SRTM DEM using K-Means Unsupervised Classification. Quaestiones Geographicae, 36(1), 93-103 DOI: 10.1515/quageo-2017-0007

Sharipkhanov, S.D., Raimbekov, K.J., Kusainov, A.B., 2015: Flood Risk Management: Methodological Handbook. Kokshetau: KTU CEM IM RK, 2015. - 92 p. URL: http://ktitjm.kz/public/uploads/BIBL_RMEB/upravlenie_riskami.pdf 